\title{
Response of Barley Genotypes to Fusarium Head Blight under Natural Infection and Artificial Inoculation Conditions
}

\author{
Raja Khanal $^{1 *}$, Thin Meiw Choo ${ }^{1}$, Allen G. Xue ${ }^{1}$, Bernard Vigier ${ }^{1}$, Marc E. Savard ${ }^{1}$, Barbara Blackwell ${ }^{1}$, \\ Junmei Wang ${ }^{2}$, Jianming Yang ${ }^{2}$, and Richard A. Martin ${ }^{3}$ \\ ${ }^{l}$ Ottawa Research and Development Centre, Agriculture and Agri-Food Canada, 960 Carling Avenue, Ottawa, Ontario \\ K1A 0C6, Canada \\ ${ }^{2}$ Chinese Barley Improvement Centre, Zhejiang Academy of Agricultural Sciences, Hangzhou, Zhejiang 310021, China \\ ${ }^{3}$ Charlottetown Research and Development Centre, Agriculture and Agri-Food Canada, 440 University Avenue, Char- \\ lottetown, Prince Edward Island C1A 4N6, Canada
}

(Received on June 8, 2021; Revised on July 28, 2021; Accepted on August 8, 2021)

Forty-eight spring barley genotypes were evaluated for deoxynivalenol (DON) concentration under natural infection across 5 years at Harrington, Prince Edward Island. These genotypes were also evaluated for Fusarium head blight (FHB) severity and DON concentration under field nurseries with artificial inoculation of $\mathbf{F u}$ sarium graminearum by the grain spawn method across 2 years at Ottawa, Ontario, and one year at Hangzhou, China. Additionally, these genotypes were also evaluated for FHB severity under greenhouse conditions with artificial inoculation of $F$. graminearum by conidial suspension spray method across 3 years at Ottawa, Ontario. The objective of the study was to investigate if reactions of barley genotypes to artificial FHB inoculation correlate with reactions to natural FHB infection. DON concentration under natural infection was positively correlated with DON concentration $(r=0.47, P<0.01)$ and FHB incidence $(r=0.56, P<0.01)$ in the artificially inoculated nursery with grain spawn method. Therefore, the grain spawn method can be used to effectively screen for low DON. FHB severity, generated from greenhouse spray, however, was not correlated with

*Corresponding author.

Phone) +1-613-759-1307, FAX) +1-613-759-1701

E-mail) raja.khanal@agr.gc.ca

Handling Editor : Jungkwan Lee

(c) This is an Open Access article distributed under the terms of the Creative Commons Attribution Non-Commercial License (http:// creativecommons.org/licenses/by-nc/4.0) which permits unrestricted noncommercial use, distribution, and reproduction in any medium, provided the original work is properly cited.

Articles can be freely viewed online at www.ppjonline.org.
DON concentration $(r=0.12, P>0.05)$ under natural infection and it was not correlated with DON concentration $(r=-0.23, P>0.05)$ and FHB incidence $(r=$ $0.19, P>0.05)$ in the artificially inoculated nursery with grain spawn method. FHB severity, DON concentration, and yield were affected by year, genotype, and the genotype $\times$ year interaction. The effectiveness of greenhouse spray inoculation for indirect selection for low DON concentration requires further studies. Nine of the 48 genotypes were found to contain low DON under natural infection. Island barley had low DON and also had high yield.

Keywords : barley, deoxynivalenol, Fusarium graminearum, Fusarium head blight, Hordeum vulgare $\mathrm{L}$.

Fusarium head blight (FHB) is a destructive disease of barley (Hordeum vulgare L.) in many warm, humid growing regions of the world. It is caused by Fusarium species, particularly $F$. graminearum. The fungi produce a range of mycotoxins, including acetyldeoxynivalenol, deoxynivalenol (DON), nivalenol, and zearalenone, which can be harmful to human and animal health (Choo, 2006). In Canada, the maximum tolerance level of DON for swine diets should not exceed $1 \mathrm{mg} / \mathrm{kg}$ as recommended by the Canadian Food Inspection Agency (Charmley and Trenholm, 2015). The use of genetic resistance is an environmentally sustainable and the most economical way to mitigate the level of DON contamination. Many breeders and pathologists have established FHB nurseries in the field to screen barley lines for DON accumulation, and many have used 
the grain spawn method to artificially inoculate the FHB nursery (Zhou et al., 1991). It is believed that disease development in the FHB nurseries would be close to that under natural infection. To our knowledge, no systematic empirical research exists addressing the question of what is the correlation between DON concentration under grain spawn inoculation and natural infection of $F$. graminearum.

Barley lines can also be screened indoor for DON accumulation. As Geddes et al. (2008) pointed out; indoor screening offers several advantages over field screening. First, indoor screening can be done throughout the calendar year. Second, it can prevent competing organisms (e.g., Bipolaris sorokiniana (Sacc.) Shoemaker) from infection. Third, its experimental error can be minimized by controlling the environmental factors and inoculum dosage. Fourth, it requires less time and labor for inoculation. If FHB symptoms are correlated well with DON concentration as reported by Choo et al. (2004), then indoor screening for FHB severity can be used for indirect selection for low DON without resorting to the time-consuming, laborintensive DON quantification. Geddes et al. (2008) concluded that indoor spray inoculation is most reproducible in comparison with point-inoculation and grain spawn. Empirical experiments are needed to determine if grain spawn inoculation or indoor spray inoculation produces similar results as those under natural infection. The objective of the study was to investigate if reactions of barley genotypes to artificial FHB inoculation with both grain spawn and indoor spray correlate well with reactions to natural FHB infection.

\section{Materials and Methods}

Plant materials. Forty-eight genotypes of spring barley were used for this study (Table 1). Many of these genotypes have shown some level of FHB resistance in previous studies or in the literature, while Brucefield, Encore, Stander, and Viviane were susceptible checks (Choo et al., 2004, 2014). These barley genotypes originated from nine countries (China, Canada, Ecuador, Japan, Germany, Sweden, Switzerland, Russia, and the United States) and included 34 two-row, two deficiens (absence of sterile lateral florets), and 12 six-row type. Six of the genotypes were hulless and 42 were covered. The genotype Birka was specifically selected for this study as its spike was partly enclosed in the upper leaf sheath from awns emergence to maturity in the field (Anonymous, 1982), which may influence infection and disease development. The genotype Kanto Nadate Gold was included because of its cleistogamy (closed flowering) as reported by Sameri et al. (2006).
Natural infection. The 48 genotypes were planted in a randomized complete block design with two replicates at the Harrington Research Farm, Charlottetown Research and Development Centre, Prince Edward Island from 2009 to 2012. Each experimental unit consisted of three rows, $3 \mathrm{~m}$ long, and $17.8 \mathrm{~cm}$ between rows. Each year, a fertilizer (17-17-17) at a rate of $412 \mathrm{~kg} / \mathrm{ha}$ (or $70 \mathrm{~kg} \mathrm{~N} / \mathrm{ha}$ ) was applied to the field before planting. The herbicide MCPA Amine 500 + Refine Extra (a.i. MCPA and thifensulfuron/ tribenuron) was sprayed at the recommended rate. Grain yield, heading date, plant height, and DON concentration was determined in each plot. For DON analysis, approximately 20 to $25 \mathrm{~g}$ of harvested barley seed was ground to pass through a $0.4 \mathrm{~mm}$ screen on a Udy-mill. To prepare extracts, $5 \mathrm{ml}$ of methanol: water $(1: 9, \mathrm{v} / \mathrm{v})$ were added to $1 \mathrm{~g}$ ground samples in $10 \mathrm{ml}$ plastic tubes, which were then subjected to end-over-end mixing for one hour, centrifuged for $5 \mathrm{~min}$ at 2,000 rpm. DON analysis was conducted on the filtrate following the enzyme-linked immunosorbent assay (ELISA) procedures described by Sinha et al. (1995). The antibody for this ELISA was developed and produced in-house and has a high affinity for both DON and 15ADON. The accuracy of the ELISA procedures has been reported to be comparable to that of the gas chromatography method (Sinha and Savard, 1996). The limit of quantitation was $0.1 \mathrm{mg} / \mathrm{kg}$. DON analysis was conducted in the mycotoxin laboratory at the Ottawa Research and Development Centre, Ottawa.

Field grain spawn inoculation. The 48 barley genotypes were seeded in a randomized complete block design with three replicates at Ottawa in 2004 and 2005, and with three replicates at Hangzhou, China in 2005. At Ottawa, the experimental materials were seeded at a seeding rate of $5 \mathrm{~g}$ per row.

Each experimental plot consisted of two 1.5-m rows with a row spacing of $15 \mathrm{~cm}$. Three $F$. graminearum isolates (DAOM178148, DAOM212678, and DAOM232369) from the Canadian National Mycological Herbarium, Ottawa Research and Development Centre, were used as inoculum for this study. These isolates were chosen since they are known to be aggressive in Canadian condition (Xue et al., 2004). Equal parts by volume of corn (Zea mays L.) and barley grain were mixed and soaked in water for 48 hours. Excess water was removed and the kernel mixture, which was placed in an aluminum pan $(53 \times 32 \times$ $8 \mathrm{~cm}^{3}$ ) and covered with two layers of aluminum foil, was autoclaved for $1 \mathrm{~h}$ at $120^{\circ} \mathrm{C}$. In each pan, $100 \mathrm{ml}$ of spore suspension of individual isolates at a concentration of $5.5 \times$ $10^{4}$ spores per $\mathrm{ml}$ was evenly poured over the surface of the 
Table 1. List of barley genotypes used and their spike type, kernel type, pedigree, and references

\begin{tabular}{|c|c|c|c|c|}
\hline Genotype & Spike & Kernel & Pedigree & Reference \\
\hline AC Alberte & 2-row & Hulless & Mimai 114/Rodeo//Rodeo & Choo et al. (2001b) \\
\hline AC Klinck & 6-row & Covered & Cadette/Chapais & Choo et al. (2001a) \\
\hline AC Minoa & 2-row & Covered & Symko/AC Sterling & Choo et al. (2010) \\
\hline AC Sterling & 2-row & Covered & Micmac/K75-10//Rodeo & Choo et al. (1994) \\
\hline ACCA & 6-row & Covered & QB730.2/UL0072//Leger/\#32 de 8 IBON & Cooper (1993) \\
\hline Atahualpa & deficiens & Hulless & Sutter/Gloria"S"/Come"S"/3/PI6384/Capuchona & Vivar et al. (1997) \\
\hline Birka & 2-row & Covered & W82-68/W17-68 & Anonymous (1982) \\
\hline Brucefield & 6-row & Covered & Maskot/Chapais & Lanoie (pers. comm.) \\
\hline CDC Freedom & 2-row & Hulless & AC Oxbow/SB88579 & Rossnagel et al. (1997) \\
\hline CGB83-46 & 2-row & Covered & UPBS76/UPBS60//UPBS60/UPBS66 & Choo et al. (2003) \\
\hline CH9419-9 & 2-row & Covered & AC Queens/Morrison & Choo (unpublished) \\
\hline CH9423-20 & 2-row & Covered & AB159-6/Morrison & Choo (unpublished) \\
\hline CH9507-8 & 2-row & Covered & DB784/Lester & Choo (unpublished) \\
\hline CH9520-30 & 2-row & Covered & DB466/AB79-17 & Choo (unpublished) \\
\hline CH9526-9 & 2-row & Covered & AC Kings/AC Sterling & Choo (unpublished) \\
\hline CH9528-10 & 2-row & Covered & AC Kings/Iona & Choo (unpublished) \\
\hline CH9625-12 & 2-row & Covered & AB162-12/Iona & Choo (unpublished) \\
\hline CH9627-3 & 2-row & Covered & AB162-12/DB200 & Choo (unpublished) \\
\hline Chapais & 6-row & Covered & QB58.14/Beacon//BT904 & Anonymous (1991) \\
\hline Chevron & 6-row & Covered & Swiss unimproved cultivar & Shands (1939) \\
\hline Chief & 2-row & Covered & DB145/AB143-3 & Choo et al. (2006a) \\
\hline CI4196 & 2-row & Covered & Chinese barley & Takeda and Heta (1989) \\
\hline Encore & 6-row & Covered & Cadette/QB198.39 & Choo et al. (2006b) \\
\hline EX645-3-6 & 2-row & Hulless & $\begin{array}{l}\text { (MSG053/B1602/BT213/806F7/CONQUEST/M82/ } \\
\text { BT946)/GAINER }\end{array}$ & Badea (pers. comm.) \\
\hline Frederickson & 2-row & Covered & Unknown & Takeda and Heta (1989) \\
\hline Golozernyj 1 & 2-row & Hulless & K-920/Odesskij-9//K-900/Kolchoznyj-Golozernyj & McCallum et al. (2004) \\
\hline Harbin-2r & 2-row & Covered & Unknown & Takeda and Heta (1989) \\
\hline Island & 2-row & Covered & CGB83-46/Rodeo//Symko & Choo et al. (2003) \\
\hline Kanto Nakate Gold & 2-row & Covered & Golden Melon/Shikoku//Kinki Shu & Sameri et al. (2006) \\
\hline Leader & 2-row & Covered & AB163-4/DB200 & Choo et al. (2009) \\
\hline M92-513 & 6-row & Covered & M87-218/Minn M69 & Rasmussion (pers. comm.) \\
\hline Maja & 2-row & Covered & Unknown & Takeda and Heta (1989) \\
\hline Mimai 114 & 2-row & Hulless & Xiaoshan Ciwangerleng/Xiaoshan Lixiahuang//Aibaiyang & Zhou et al. (1991) \\
\hline Myriam & 6-row & Covered & OB339-1/Bedford & Bastien (pers. comm.) \\
\hline Niedzica 1 & 2-row & Covered & Unknown & Takeda and Heta (1989) \\
\hline OAC Kippen & 6-row & Covered & OB141-1/Perth & Falk and Reinbergs (1991) \\
\hline Orthega & 2-row & Covered & Ceb.7931/Pompadour//S.77323/Golf & Buerstmayr et al. (2004) \\
\hline Peatland & 6-row & Covered & Swiss unimproved cultivar & Immer and Christensen (1943) \\
\hline Primus & 2-row & Covered & Unknown & Takeda and Heta (1989) \\
\hline Rodeo & 2-row & Covered & UPBS60/UPBS76 & Campbell et al. (1984) \\
\hline Shyri & deficiens & Covered & Lignee 640/Kober//Teran 78 & Vivar et al. (1997) \\
\hline Stander & 6-row & Covered & Excel/M80-224 & Rasmusson et al. (1993) \\
\hline Symko & 2-row & Covered & Rodeo/Gitane & Нo (1990) \\
\hline Viviane & 6-row & Covered & Maskot/Chapais & Lanoie (pers. comm.) \\
\hline Zaoshu 3 & 2-row & Covered & Kanto Nijo 3 & Gao (1989) \\
\hline Zhedar 1 & 2-row & Covered & Chinese barley & Urrea et al. (2005) \\
\hline Zhedar 2 & 2-row & Covered & Chinese barley & Urrea et al. (2005) \\
\hline Zhenongda 3 & 2-row & Covered & $76-6477 / 76-20$ & Ding et al. (1987) \\
\hline
\end{tabular}


kernel mixture in a laminar flow hood. The kernel mixture was incubated at room temperature for each isolate for at least 4 weeks. Kernels infected with the three isolates were mixed in the same proportion and then broadcast at a rate of $50 \mathrm{~g}$ per $\mathrm{m}^{2}$ once in 2004 (July 5 at late stem elongation) and at a rate of $30 \mathrm{~g}$ per $\mathrm{m}^{2}$ twice in 2005 (June 22 at early stem elongation and June 28 at booting). Shortly after inoculation, the plots were watered with a sprinkler system twice a day (at 11:00-11:30 am and 3:00-4:00 pm) for 20$30 \mathrm{~min}$ to increase the humidity.

Heading date, plant height, and FHB incidence (i.e., percentage of heads infected per row) were recorded. DON concentration was determined at Ottawa for all plots using the ELISA method as described earlier.

At Hangzhou, China, the experimental materials were seeded at a seeding rate of $5 \mathrm{~g}$ per row. Each plot consisted of one $1.5-\mathrm{m}$ row with a row spacing of $30 \mathrm{~cm}$. A mixture of $F$. graminearum isolates collected from the cultivar Giu Damai from Hailing, Zhejiang was multiplied on a potato-dextrose-agar (PDA) medium at $28^{\circ} \mathrm{C}$ for 10 days. Wheat kernels were soaked in water for $24 \mathrm{~h}$, put in 1-1 glass bottles, and then autoclaved for $30 \mathrm{~min}$ at $120^{\circ} \mathrm{C}$. The wheat kernels were inoculated with the $F$. graminearum mycelium at five positions in a glass bottle and incubated at $25^{\circ} \mathrm{C}$ for 10 days. Infected wheat kernels were broadcast at a rate of $7.5 \mathrm{~g}$ per $\mathrm{m}^{2}$ at the booting stage. At heading, all plots were also sprayed with a $F$. graminearum suspension. There was no supplementary water of the inoculated plots at this location. Heading date, plant height, and FHB incidence (i.e., percentage of heads infected per row) were recorded. DON concentration was determined for all plots at Ottawa using the ELISA method as described natural infection section of this study.

Indoor spray inoculation. Three greenhouse trials were conducted at the Ottawa Research and Development Centre, Ottawa, from January to June each year in 2005, 2006 and 2007, using the same three isolates (DAOM178148, DAOM212678, and DAOM232369) as in grain spawn inoculation. The isolates were cultured on a modified PDA $(10 \mathrm{~g} / \mathrm{l}$ of dextrose amended with $34 \mathrm{~mol} / \mathrm{l}$ streptomycin sulfate) and incubated at $22-25^{\circ} \mathrm{C}$ under mixed UV and fluorescent lighting on a $12 \mathrm{~h}$ light: $12 \mathrm{~h}$ dark cycle for 14 days. The modified PDA medium was used to reduce mycelium growth, possible mutation, and poor vigour, and to increase spore production by the pathogen (Xue et al., 2004). To prepare inoculum, $0.5 \mathrm{ml}$ of a concentrated macroconidial suspension (approx. 107 spores $/ \mathrm{ml}$ ), obtained from the above, was spread over the surface of the modified PDA in 9-cm Petri dishes and incubated as described above for $48 \mathrm{~h}$. Ten millilitres of sterile distilled water containing $0.01 \%$ Tween 20 (polyoxyethylene sorbitan monolaurate) was then added to each dish, and the surface was scraped gently with a sterile microscope slide to dislodge spores. The resulting conidial suspension was filtered through two layers of cheesecloth and adjusted to a concentration of 5 $\times 10^{4}$ spores $/ \mathrm{ml}$ using a hemocytometer. Separate conidial suspensions were prepared for each isolate. The final suspension used for the greenhouse consisted of 1:1:1 mixture of each of the three $F$. grameniarum isolates.

The seeds of 48 barley genotypes were planted in 15$\mathrm{cm}$ diameter pots containing a mixture of loam soil, sand, and composted cow manure $(1: 1: 1, \mathrm{v} / \mathrm{v} / \mathrm{v})$ and maintained at $23-25^{\circ} \mathrm{C}$ during the day and $18-20^{\circ} \mathrm{C}$ at night in a greenhouse. Supplemental light was provided by $300 \mathrm{~W}$ metal halide lamps to ensure a $16 \mathrm{~h}$ photoperiod and a minimum intensity of $360 \mathrm{~mol} / \mathrm{m}^{2} / \mathrm{s}$. Plants were fertilized with a $1 \%$ solution of 20-20-20 (N-P-K) at the fifth week after planting and once per week thereafter. The 48 barley genotypes were inoculated 10-14 days after heading. Plants were sprayed with the spore suspension at approximately 0.2 $\mathrm{ml}$ per spike using a DeVilbiss model 15 atomizer (The DeVilbiss Co., Somerset, PA, USA). After the inoculum dried for $30 \mathrm{~min}$, plants were transferred to a polyethylene humidity chamber in a growth room for $24 \mathrm{~h}$. The growth room was operated at $25^{\circ} \mathrm{C}$ with 12 -h photoperiod at a light intensity of $250 \mathrm{~mol} / \mathrm{m}^{2} / \mathrm{s}$. The humidity chamber was maintained at or near $100 \%$ relative humidity by the continuous operation of two ultrasonic humidifiers. Air temperature and humidity in the chamber were monitored with a portable datalogger (model 21XL micrologger, Campbell Scientific Canada Corp., Edmonton, AB, Canada). After incubation, plants were returned to the greenhouse bench. For each barley genotype, eight replicate pots were used in 2005 and 2006 and four replicate pots in 2007. Pots were arranged in a completely randomized design in both the humidity chamber and the greenhouse after the inoculation. The severity of FHB was rated as the percentage of infected spikelets 21-23 days after inoculation when plants were at the soft dough stage.

Statistical analysis. Data were analyzed using the MIXED procedure of the SAS software (SAS Institute, 2004). The genotype was considered to be a fixed effect and all of the other terms (year, rep [year], and genotype year) to be random effects. Log-transformed DON data were used to perform the analysis of variance. Means over all of the trials in each experiment were used for calculating Pearson correlation coefficients. Pearson correlation coefficient was calculated to determine (1) if DON concentration was cor- 
related with any of the three agronomic traits (yield, height, and heading date) in the natural infection experiment, (2) if DON concentration was correlated with FHB incidence, height, and heading date in the grain spawn experiment, (3) if DON concentration under natural infection was correlated with DON concentration and FHB incidence with grain spawn inoculation, and (4) if FHB severities with indoor spray inoculation were correlated with DON concentration under natural infection and DON concentration and FHB incidence with grain spawn inoculation.

\section{Results}

Natural infection. There was a significant $(P<0.05)$ variation among genotypes for all four traits (Table 2). DON contamination was greatest in 2009 and 2010, intermediate in 2011, and low in 2012 and 2013. The mean yield was similar from year to year. Plant height was tall in 2009 , 2010, and 2011, but short in 2012 and 2013. The heading date was early in 2009, 2011, and 2012, but late in 2010 and 2013 (Table 2). There was a significant genotype-year interaction for DON concentration, yield, plant height, and heading date (Table 3). The genotype-year interaction can be attributed to a change in magnitude of mean DON concentration in different years. All of these barley genotypes were contaminated with DON (Table 4). DON concentration of these genotypes was either positively correlated or not correlated between the 5 years. Positive correlation was detected between 2009 and $2010(r=0.69, P<0.01)$, between 2009 and $2011(r=0.76, P<0.01)$, between 2009 and $2012(r=0.41, P<0.01)$, between 2010 and $2011(r=$ $0.60, P<0.01)$, and between 2011 and $2012(r=0.43, P<$ $0.01)$. Two-row genotypes, in general, contained less DON than six-row genotypes except Zhenongda 3, Zaosho 3, Mimai 114, CH9528-10, and Kanto Nakate Gold (Table 4). The two deficiens genotypes contained an average amount of DON. Hulless genotypes generally contained less DON than covered genotypes with the exception of Mimai 114. Only nine genotypes (Island, Zhedar 1, Golozernyj 1, Harbin 2r, CDC Freedom, Zhedar 2, Maja, CH9507-8, and Niedzica 1) from 2-row barley contained less than $1 \mathrm{mg}$ DON kg-1, which is the recommended maximum tolerance level of DON for swine diets in Canada. These nine genotypes were generally tall (ranging from $77 \mathrm{~cm}$ to 96 $\mathrm{cm}$ ) and late in the heading date (ranging from 60 to 64 days) (Table 4). Of the nine genotypes that had low DON,

Table 2. Mean of heading date, height, DON, fusarium head blight severity and incidence and yield in natural infection and artificial infection with Fusarium graminearum in five and three environments averaged across 48 barley genotypes

\begin{tabular}{|c|c|c|c|c|c|c|c|c|c|c|c|}
\hline \multicolumn{5}{|c|}{ Natural infection } & \multicolumn{5}{|c|}{ Field artificial inoculation } & \multicolumn{2}{|c|}{ Indoor spray inoculation } \\
\hline Environment & $\begin{array}{c}\text { Heading } \\
\text { (day) }\end{array}$ & $\begin{array}{l}\text { Height } \\
\text { (cm) }\end{array}$ & $\begin{array}{c}\text { DON } \\
(\mathrm{mg} / \mathrm{kg})\end{array}$ & $\begin{array}{l}\text { Yield } \\
\text { (t/ha) }\end{array}$ & Environment & $\begin{array}{c}\text { Heading } \\
\text { (day) }\end{array}$ & $\begin{array}{c}\text { Height } \\
(\mathrm{cm})\end{array}$ & $\begin{array}{c}\text { Incidence } \\
(\%)\end{array}$ & $\begin{array}{c}\text { DON } \\
(\mathrm{mg} / \mathrm{kg})\end{array}$ & Environment & $\begin{array}{c}\text { Severity } \\
(\%)\end{array}$ \\
\hline Harrington 2009 & $55 \mathrm{D}$ & $92 \mathrm{~A}$ & $3.19 \mathrm{~A}$ & $2.92 \mathrm{~A}$ & Ottawa 2004 & $53 \mathrm{~B}$ & $78 \mathrm{C}$ & $42 \mathrm{~A}$ & $6.3 \mathrm{~A}$ & Ottawa 2005 & $47.42 \mathrm{~A}$ \\
\hline Harrington 2010 & $68 \mathrm{~A}$ & $86 \mathrm{~B}$ & $3.47 \mathrm{~A}$ & $3.09 \mathrm{~A}$ & Ottawa 2005 & $50 \mathrm{C}$ & $85 \mathrm{~B}$ & $35 \mathrm{~B}$ & $7.5 \mathrm{~A}$ & Ottawa 2006 & $40.51 \mathrm{~A}$ \\
\hline Harrington 2011 & $54 \mathrm{E}$ & $92 \mathrm{~A}$ & $2.09 \mathrm{~B}$ & $2.94 \mathrm{~A}$ & Hangzhou 2005 & $141 \mathrm{~A}$ & $100 \mathrm{~A}$ & $7 \mathrm{C}$ & $1.6 \mathrm{~B}$ & Ottawa 2007 & $23.15 \mathrm{~B}$ \\
\hline Harrington 2012 & $57 \mathrm{C}$ & $76 \mathrm{C}$ & $0.30 \mathrm{C}$ & $3.29 \mathrm{~A}$ & - & - & - & - & - & - & - \\
\hline Harrington 2013 & $64 \mathrm{~B}$ & $70 \mathrm{D}$ & $0.61 \mathrm{C}$ & $2.43 \mathrm{~A}$ & - & - & - & - & - & - & - \\
\hline
\end{tabular}

DON, deoxynivalenol.

Table 3. Analysis of variance of heading date, height, DON, Fusarium head blight severity and incidence and yield in natural infection and artificial infection with Fusarium graminearum in five and three environments

\begin{tabular}{|c|c|c|c|c|c|c|c|c|c|c|c|c|}
\hline \multirow{2}{*}{ Source } & \multicolumn{5}{|c|}{ Natural infection } & \multicolumn{5}{|c|}{ Field artificial infection } & \multicolumn{2}{|c|}{ Indoor spray } \\
\hline & DF & Heading & Height & $\log (\mathrm{DON})$ & Yield & DF & Heading & Height & Incidence & $\log (\mathrm{DON})$ & DF & Severity \\
\hline Environment & 4 & $3,855^{* *}$ & $8,937 *$ & $91.11^{* *}$ & 9.25 & 2 & $366,715^{* *}$ & $18,597 * *$ & $47,400 * *$ & $63.7 * *$ & 2 & $35,008 * *$ \\
\hline Rep (Environment) & 5 & $14^{* *}$ & $999 * *$ & $0.42 * *$ & $6.26^{* *}$ & 6 & 10 & $341 * *$ & $340 *$ & $1.6^{* *}$ & 17 & 677 \\
\hline Genotype & 47 & $104 * *$ & $648 * *$ & $2.20 * *$ & $5.63 * *$ & 47 & $171 * *$ & $536^{* *}$ & $902 *$ & $4.5^{* *}$ & 47 & $2,388 * *$ \\
\hline $\begin{array}{l}\text { Environment } \times \\
\text { Genotype }\end{array}$ & 182 & $5^{* *}$ & $47 * *$ & $0.59 * *$ & $0.48^{* *}$ & 87 & $26^{* *}$ & $125^{* *}$ & $508 * *$ & $1.2^{* *}$ & 91 & $1,062 * *$ \\
\hline Error & 228 & 1 & 30 & 0.12 & 0.19 & 263 & 5 & 45 & 123 & 0.3 & 718 & 507.9 \\
\hline
\end{tabular}

DON, deoxynivalenol.

$*$, **, and ***, significant at $P \leq 0.05, P \leq 0.01$, and $P \leq 0.001$, respectively. 
Table 4. Mean of heading date, height, DON, Fusarium head blight severity and incidence and yield of 48 barley genotypes grown under natural infection at Harrington, Prince of Edward Island (2009-2013), artificial infection with grain spawn method at Ottawa (2004 and 2005) and Hangzhou, China (2005) and indoor spray method at Ottawa (2004 to 2006)

\begin{tabular}{|c|c|c|c|c|c|c|c|c|c|}
\hline \multirow[b]{2}{*}{ Genotype } & \multicolumn{4}{|c|}{ Natural infection } & \multicolumn{4}{|c|}{ Field artificial infection } & \multirow{2}{*}{$\begin{array}{c}\text { Indoor spray } \\
\text { FHB severity } \\
(\%)\end{array}$} \\
\hline & $\begin{array}{c}\text { Heading } \\
\text { (day) }\end{array}$ & $\begin{array}{l}\text { Height } \\
(\mathrm{cm})\end{array}$ & $\begin{array}{c}\text { DON } \\
(\mathrm{mg} / \mathrm{kg})\end{array}$ & $\begin{array}{c}\text { Yield } \\
\text { (kg/ha) }\end{array}$ & $\begin{array}{l}\text { Heading } \\
\text { (day) }\end{array}$ & $\begin{array}{l}\text { Height } \\
(\mathrm{cm})\end{array}$ & $\begin{array}{c}\text { Incidence } \\
(\%)\end{array}$ & $\begin{array}{c}\text { DON } \\
(\mathrm{mg} / \mathrm{kg})\end{array}$ & \\
\hline Island & 60 & 85 & 0.4 & 3,750 & 77 & 92 & 29 & 3.6 & 23.7 \\
\hline Zhedar 1 & 62 & 86 & 0.5 & 1,730 & 87 & 98 & 24 & 1 & 21.9 \\
\hline Golozernyj 1 & 60 & 94 & 0.6 & 2,100 & 83 & 91 & 15 & 2 & 23.3 \\
\hline Harbin-2r & 61 & 96 & 0.6 & 2,790 & 85 & 99 & 18 & 1.1 & 27.4 \\
\hline CDC Freedom & 62 & 87 & 0.7 & 2,340 & 85 & 86 & 14 & 2.1 & 18.3 \\
\hline Zhedar 2 & 63 & 88 & 0.7 & 2,150 & 88 & 92 & 20 & 1.5 & 13.4 \\
\hline Maja & 63 & 89 & 0.8 & 2,450 & 86 & 85 & 23 & 4.3 & 22.0 \\
\hline CH9507-8 & 61 & 91 & 0.9 & 3,750 & 80 & 88 & 29 & 2.7 & 25.3 \\
\hline Niedzica 1 & 64 & 77 & 0.9 & 2,600 & 87 & 87 & 17 & 1.7 & 24.7 \\
\hline EX645-3-6 & 59 & 92 & 1 & 2,950 & 85 & 87 & 18 & 1.6 & 29.2 \\
\hline Leader & 58 & 88 & 1.1 & 3,760 & 78 & 85 & 30 & 4 & 28.7 \\
\hline CH9526-9 & 61 & 84 & 1.1 & 3,990 & 80 & 86 & 36 & 3.2 & 27.5 \\
\hline Symko & 62 & 74 & 1.1 & 3,350 & 80 & 88 & 34 & 3.4 & 16.5 \\
\hline СH9419-9 & 61 & 93 & 1.1 & 3,770 & 80 & 88 & 27 & 4.2 & 27.8 \\
\hline Primus & 62 & 95 & 1.1 & 1,930 & 88 & 101 & 22 & 3.3 & 19.5 \\
\hline Rodeo & 61 & 78 & 1.1 & 2,790 & 84 & 85 & 16 & 2.4 & 34.8 \\
\hline Frederickson & 62 & 91 & 1.1 & 2,050 & 87 & 104 & 21 & 1.3 & 27.2 \\
\hline Chief & 59 & 90 & 1.2 & 3,450 & 80 & 90 & 30 & 3.8 & 28.1 \\
\hline Birka & 63 & 76 & 1.2 & 3,300 & 85 & 75 & 33 & 2.1 & 23.2 \\
\hline Orthega & 63 & 63 & 1.2 & 3,030 & 86 & 69 & 18 & 4.5 & 12.4 \\
\hline Atahualpa & 60 & 68 & 1.2 & 1,890 & 86 & 78 & 14 & 2.5 & 26.9 \\
\hline CH9520-30 & 59 & 88 & 1.2 & 3,470 & 79 & 84 & 34 & 5 & 8.9 \\
\hline AC Minoa & 59 & 86 & 1.3 & 3,790 & 79 & 87 & 22 & 1.7 & 21.0 \\
\hline CI4196 & 69 & 83 & 1.3 & 1,150 & 92 & 99 & 17 & 2.1 & 17.9 \\
\hline AC Sterling & 61 & 83 & 1.3 & 3,450 & 81 & 85 & 23 & 3 & 11.8 \\
\hline AC Alberte & 60 & 80 & 1.3 & 2,700 & 80 & 86 & 15 & 2.7 & 14.3 \\
\hline CH9423-20 & 59 & 83 & 1.3 & 3,790 & 79 & 85 & 34 & 2.9 & 12.4 \\
\hline CGB83-46 & 64 & 66 & 1.4 & 2,450 & 83 & 68 & 38 & 7 & 23.8 \\
\hline CH9627-3 & 59 & 87 & 1.5 & 3,920 & 79 & 85 & 25 & 2.7 & 9.0 \\
\hline CH9625-12 & 59 & 84 & 1.6 & 3,480 & 81 & 90 & 34 & 2.5 & 21.4 \\
\hline Chevron & 56 & 98 & 1.9 & 2,840 & 75 & 104 & 13 & 1.6 & 18.0 \\
\hline M92-513 & 60 & 94 & 2.1 & 3,100 & 78 & 96 & 12 & 2.4 & 14.3 \\
\hline Kanto Nakate Gold & 57 & 70 & 2.1 & 1,900 & 77 & 77 & 52 & 25.8 & 9.2 \\
\hline Myriam & 57 & 83 & 2.3 & 3,360 & 77 & 89 & 40 & 6.8 & 23.6 \\
\hline OAC Kippen & 58 & 81 & 2.3 & 3,370 & 76 & 92 & 28 & 4.8 & 22.8 \\
\hline AC Klinck & 61 & 86 & 2.3 & 3,520 & 80 & 90 & 27 & 4.3 & 21.1 \\
\hline CH9528-10 & 58 & 87 & 2.7 & 3,750 & 78 & 87 & 35 & 3.5 & 20.1 \\
\hline Shyri & 58 & 84 & 2.7 & 2,400 & 81 & 92 & 41 & 5.7 & 26.0 \\
\hline Chapais & 56 & 72 & 2.9 & 3,140 & 77 & 80 & 43 & 11.7 & 12.0 \\
\hline Zhenongda 3 & 50 & 68 & 3 & 1,670 & 70 & 73 & 41 & 40.7 & 29.4 \\
\hline Zaoshu 3 & 50 & 72 & 3.2 & 1,740 & 71 & 75 & 39 & 3.9 & 18.5 \\
\hline ACCA & 58 & 85 & 3.8 & 3,740 & 79 & 86 & 41 & 3.1 & 31.2 \\
\hline Encore & 62 & 86 & 3.8 & 3,450 & 82 & 92 & 38 & 7.2 & 21.3 \\
\hline Viviane & 60 & 86 & 3.9 & 3,460 & 83 & 90 & 44 & 9.6 & 28.3 \\
\hline Stander & 58 & 80 & 4.6 & 3,410 & 75 & 74 & 48 & 15.5 & 6.8 \\
\hline Mimai 114 & 55 & 74 & 5.4 & 1,440 & 77 & 82 & 34 & 15.2 & 12.9 \\
\hline Brucefield & 56 & 80 & 5.8 & 3,480 & 76 & 83 & 46 & 14.3 & 14.5 \\
\hline Peatland & 57 & 87 & 5.9 & 2,760 & 77 & 94 & 26 & 5.2 & 3.5 \\
\hline
\end{tabular}

DON, deoxynivalenol. 
Island and CH9507-8 had high yield (3,700 kg/ha) while the others had low yield $(<2,800 \mathrm{~kg} / \mathrm{ha})$ (Table 4$)$. The correlation coefficient between DON concentration and grain yield for all genotypes was not significant at the 0.05 level (Table 5). Plant height was not correlated with DON concentration, but heading date was negatively correlated with DON concentration (Table 5). Heading date remained negatively correlated with DON concentration even when the two earliest heading dates (at least 5 days earlier under natural infection) genotypes (Zhenongda 3 and Zaoshu 3) were excluded from the correlation analysis.

Grain spawn inoculation. On average, these 48 genotypes at Ottawa, Ontario had higher DON, higher FHB incidence, and shorter and headed earlier than those at Hangzhou, China (Table 2). Variation for all four traits among genotypes was significant, so were environment $\mathrm{x}$ genotype interactions for all four traits (Table 3). The nine resistant genotypes contained low DON, ranging from 1.0 to $4.3 \mathrm{mg} / \mathrm{kg}$ with grain spawn inoculation (Table 4). Two genotypes, Kanto Nakate Gold $(25.8 \mathrm{mg} / \mathrm{kg})$ and Zhenongda $3(40.7 \mathrm{mg} / \mathrm{kg})$, contained an extremely high concentration of DON and they were considered far outliers (Table 4). When these two outliers (Kanto Nakate Gold and Zhenongda 3 ) were excluded from the correlation analysis, the correlation coefficient for DON concentration was highly positive between the three environments, i.e., between Ottawa 2004 and Ottawa $2005(r=0.79, P<0.01)$, between Ottawa 2004 and Hangzhou $2005(r=0.44, P<0.01)$, and between Ottawa 2005 and Hangzhou $2005(r=0.43, P<$ $0.01)$. In this experiment, DON concentration was positively correlated with FHB incidence, but it was negatively correlated with height and heading date (Table 5). Heading date negatively correlated with DON concentration even when the two earliest heading genotypes (Zhenongda 3 and Zaoshu 3) were excluded from the correlation analysis.

Indoor spray inoculation. FHB severity varied from year to year and from genotype to genotype (Table 2). There were significant interactions between year and genotype (Table 3). The nine resistant genotypes were relatively low in FHB severity, ranging from $24 \%$ to $39 \%$, but early heading genotypes such as Zhenongda-3, Zaoshu-3, Mimai-114, and Kanto Nakate Gold had even lower FHB severity ( $8 \%$ to $18 \%$ ) (Table 4). DON concentration and FHB incidence with grain spawn inoculation were positively correlated with DON concentration obtained from natural infection (Table 5). When the two outliers (Kanto Nakate Gold and Zhenongda-3) were excluded from the correlation analysis the correlation coefficient for DON concentration between
Table 5. Pearson correlation coefficients between FHB parameters (FHB incidence, FHB severity, and DON content) and additionally investigated traits under natural infection, artificial grain spawn method and indoor spray conditions

\begin{tabular}{lc}
\hline \multicolumn{1}{c}{ Traits } & $\begin{array}{c}\text { Correlation } \\
\text { coefficient }\end{array}$ \\
\hline Natural infection DON and natural infection yield & 0.01 \\
Natural infection DON and natural infection & -0.21 \\
$\quad$ height & $-0.53^{* *}$ \\
Natural infection DON and natural infection & \\
$\quad$ heading & $0.59^{* *}$ \\
Grain spawn DON and grain spawn FHB inci- & \\
$\quad$ dence & $-0.46^{* *}$ \\
Grain spawn DON and grain spawn height & $-0.52^{* *}$ \\
Grain spawn DON and grain spawn heading & $0.47^{* *}$ \\
Natural infection DON and grain spawn DON & $0.56^{* *}$ \\
Natural infection DON and grain spawn FHB & \\
$\quad$ incidence & 0.12 \\
Natural infection DON and indoor spray FHB & \\
$\quad$ severity & \\
Grain spawn DON and indoor spray FHB severity & -0.23 \\
\hline
\end{tabular}

FHB, Fusarium head blight; DON, deoxynivalenol.

natural infection and grain spawn increased from $r=0.47$ 0.76 . FHB severity with indoor spray inoculation was not correlated with DON concentration $(r=0.12)$ under natural infection, and similarly, FHB severity with indoor spray inoculation was not correlated with DON concentration $(r$ $=-0.23)$ and FHB incidence $(r=0.19)$ under grain spawn (Table 5).

\section{Discussion}

To our knowledge, this is the first report on the FHB relationships between artificial inoculation and natural infection in barley. Our results showed that reactions to DON accumulation with grain spawn inoculation were positively correlated with those under natural infection. Despite that grain spawn inoculation was conducted in Ottawa, Ontario, and Hangzhou, China which is far away from Harrington, DON data from grain spawn inoculation were positively correlated between the three environments and also with those under natural infection. This suggests that grain spawn inoculation can be conducted outside the epidemic area and can still effectively identify lines with low DON. In contrast, FHB severity in indoor spray inoculation showed no correlation with DON accumulation under natural infection and no correlation with DON accumulation and FHB incidence with grain spawn inoculation. Some of the early genotypes such as Zhenongda 3 and 
Mimai 114 were low in FHB severity with indoor spray inoculation, but they were very susceptible under natural infection and with grain spawn method in artificial inoculation. On the other hand, Rodeo was relatively low in DON concentration under natural infection but it was one of the most susceptible to FHB with indoor spray inoculation. In the indoor spray inoculation, data for FHB severities were collected 21-23 days after inoculation. This short time may not allow for the complete determination of the full impact of the spread of infection within a plant. Some early genotypes could be susceptible to fungal spread (dense spike); while Rodeo and others could be susceptible to initial infection, but they could be resistant to fungal spread. The results suggest that the effectiveness of indoor spray inoculation for indirect selection for low DON requires further studies.

Previously, Geddes et al. (2008) evaluated 19 barley genotypes for FHB responses with three inoculation methods (point or spray inoculation in the greenhouse and grain spawn in a field nursery). Significant genotypic differences for FHB symptoms were detected for all three inoculation methods; a significant difference for DON concentration, however, was detected only in one, point-inoculation, experiment. They concluded that indoor spray inoculation was the most reproducible method for phenotypic evaluation because it mimics natural infection. No evaluation of the 19 genotypes was conducted under natural infection in Geddes et al. (2008) study. This study indicated that indoor spray showed a different response to FHB than under natural infection.

In this study, nine out of the 48 barley genotypes were found to have low DON, with an average of $<1 \mathrm{mg} \mathrm{DON} /$ $\mathrm{kg}$ under natural infection. Of the nine low-DON genotypes, $\mathrm{CH} 9507-8$ and Island yielded significantly higher than the other seven genotypes. Choo et al. (2003) were the first to report low DON in Island barley. Choo et al. (2004) again reported that Island, along with AC Alberte and Chevron, were found to be most resistant, as they were consistently low in FHB incidence and DON concentration. Geddes et al. (2008) has also reported that Island was one of the genotypes with a low FHB rating and low DON in their 5-year study with the grain spawn method. All of these results indicate that Island can be used to mitigate DON contamination in Eastern Canada. Island has been on the cultivar recommended list for Atlantic Canada since 2004 and for Quebec since 2006.

The pedigree of Island is CGB83-46/Rodeo//Symko, in which CGB83-46 and Symko are each half related to Rodeo (Table 1). Therefore, Island is genetically very close to
Rodeo as its ancestors are either Rodeo or Rodeo-related genotypes. Another most resistant genotype CH9507-8 is also related to Rodeo because one of its parents Lester was derived from a UPBS60/UPBS66//Rodeo cross. AC Alberte was relatively low in DON concentration (Choo et al., 2004) and it was derived from a backcross of Mimai-114/ Rodeo//Rodeo. The resistance of AC Alberte to DON accumulation must have come from Rodeo because Rodeo was quite resistant to DON accumulation while Mimai-114 was very susceptible to DON accumulation (also see Urrea et al., 2005). Other Rodeo-derived genotypes (including AC Minoa, AC Sterling, and CH9526-9) contained low DON in response to FHB infection under natural infection. These suggest that resistance to DON accumulation of Island mainly originates from the genotype Rodeo.

The nine genotypes that contained low DON include two hulless barley, Golozernyj 1 and CDC Freedom. But the yield of these two hulless genotypes was very low $(2,100$ $2,300 \mathrm{~kg} / \mathrm{ha}$ ). It has been suggested that deficiens barley is associated with FHB resistance (Vivar et al., 1997). The two deficiens genotypes in this study, however, were contaminated with DON considerably. These results do not support the notion that deficiens barley is associated with FHB resistance. The cleistogamous genotype Kanto Nakate Gold was susceptible to DON accumulation under both natural infection and grain spawn inoculation. Yoshida et al. (2007) pointed out that cleistogamous cultivars are resistant to FHB infection at anthesis but susceptible at 10 days after anthesis. Birka was relatively low in DON concentration in both natural infection and grain spawn inoculation. Maybe its upper leaf sheath did provide some protection from FHB infection as its spike was partially enclosed in the upper leaf sheath from awn emergence to maturity in the field.

In conclusion, artificial inoculation with the grain spawn method produced a similar response to DON accumulation as natural infection, and thus it can be used to effectively screen for low DON. In contrast, artificial inoculation with indoor spray inoculation produced a profile of FHB severities that had no relation with the profile of DON concentration under natural infection and had no relation with the profiles of DON concentration and FHB incidence with grain spawn inoculation. Further studies are required to determine the DON relationship between indoor spray inoculation and natural infection. Nine barley genotypes were found to contain low DON under natural infection. Among these, Island barley not only had low DON but also had high yield. 


\section{Conflicts of Interest}

No potential conflict of interest relevant to this article was reported.

\section{Acknowledgments}

The authors were grateful to Professor K. Takeda (Research Institute for Bioresources, Japan), Dr. T. Makino (National Agriculture Research Centre, Japan), Professors S. Ding and S. Xu (Zhejiang Agricultural University, China), Professor D. Rasmussion (University of Minnesota, USA), and Dr. Bill Legge (Brandon Research and Development Centre, Canada) for providing seeds of barley genotypes, and to Yuanhong Chen, Sally Buffam, and Sharon ter Beek for their assistance in conducting this study.

\section{References}

Anonymous. 1982. Description of variety: Birka. Agriculture Canada, Ottawa, ON, Canada, pp. 1061-1062.

Anonymous. 1991. Description of variety: Chapais. Agriculture Canada, Ottawa, ON, Canada.

Buerstmayr, H., Legzdina, L., Steiner, B. and Lemmens, M. 2004. Variation for resistance to Fusarium head blight in spring barley. Euphytica 137:279-290.

Campbell, K. W., Brawn, R. I. and Ho, K. M. 1984. Rodeo barley. Can. J. Plant Sci. 64:203-205.

Charmley, L. L. and Trenholm, H. L. 2015. Fact sheet: mycotoxins. URL http://www.inspection.gc.ca/animals/feeds/regulatory-guidance/rg-8/eng/1347383943203/1347384015909?chap $=0 \#$ s1c1 [13 August 2021].

Choo, T. M. 2006. Breeding barley for resistance to Fusarium head blight and mycotoxin accumulation. Plant Breed. Rev. 26:125-169.

Choo, T. M., Ho, K. M., Martin, R. A. and ter Beek, S. 2001a. AC Klinck barley. Can. J. Plant Sci. 81:431-432.

Choo, T. M., Ho, K. M., Martin, R. A., ter Beek, S. M., Dion, Y. and Rioux, S. 2006a. Chief barley. Can. J. Plant Sci. 86:485-487.

Choo, T. M., Ho, K. M., ter Beek, S. M., Martin, R. A., Dion, Y. and Rioux, S. 2006b. Encore barley. Can. J. Plant Sci. 86:489-491.

Choo, T. M., Martin, R. A., Ho, K. M., Bubar, J. S., Walton, R., Blatt, R. and Rodd, V. 1994. AC Sterling barley. Can. J. Plant Sci. 74:817-819.

Choo, T. M., Martin, R. A., Ho, K. M., Shen, Q., Fedak, G., Savard, M., Voldeng, H., Falk, D. E., Etienne, M. and Sparry, E. 2004. Fusarium head blight and deoxynivalenol accumulation of barley in Eastern Canada: cultivar response and correlation analysis. Plant Dis. 88:837-844.

Choo, T. M., Martin, R. A., Savard, M. E. and Blackwell, B. 2014. Effects of planting date and earliness on deoxynivale- nol contamination in barley under natural epidemic conditions. Can. J. Plant Sci. 94:1363-1371.

Choo, T. M., Martin, R. A., ter Beek, S. M., Caldwell, C. D., Price, M., Rowsell, J., Dion, Y., Rioux, S. and Pageau, D. 2009. Leader barley. Can. J. Plant Sci. 89:921-924.

Choo, T. M., Martin, R. A., ter Beek, S., Ho, K. M., Caldwell, C. D., Walker, D. and Rodd, V. 2001b. AC Alberte hulless barley. Can. J. Plant Sci. 81:425-426.

Choo, T. M., Martin, R. A., ter Beek, S. M., Ho, K. M., Caldwell, C. D., Walker, D., Rodd, V., Dion, Y. and Rioux, S. 2003. Island barley. Can. J. Plant Sci. 83:793-795.

Choo, T. M., ter Beek, S. M., Martin, R. A. and Rowsell, J. 2010. AC Minoa. Can. J. Plant Sci. 90:869-871.

Cooper, G. W. 1993. Report on eastern six row barley registration test. Plant Research Centre, Agriculture Canada, Ottawa, ON, Canada.

Ding, S., Xu, S., Guan, M. and Huang, J. 1987. Breeding, characteristics, and key cultural practices of barley cultivar Zhenongda 3. Zhejiang Agric. Sci. 6:251-254 (in Chinese).

Falk, D. E. and Reinbergs, E. 1991. OAC kippen spring barley. Can. J. Plant Sci. 71:205-206.

Gao, D. S. 1989. Zaoshu 3. In: Annals of barley cultivars in China, pp. 32-32. Agriculture Press, Beijing, China (in Chinese).

Geddes, J., Eudes, F., Tucker, J. R., Legge, W. G. and Selinger, L. B. 2008. Evaluation of inoculation methods on infection and deoxynivalenol production by Fusarium graminearum on barley. Can. J. Plant Pathol. 30:66-73.

Ho, K. M. 1990. Symko barley. Can. J. Plant Sci. 70:853-854.

Immer, F. R. and Christensen, J. J. 1943. Studies on susceptibility of varieties and strains of barley to Fusarium and Helminthosporium kernel blight when tested under muslin tents or in nurseriess. J. Am. Soc. Agron. 35:515-522.

McCallum, B. D., Tekauz, A. and Gilbert, J. 2004. Reaction of a diverse collection of barley lines to Fusarium head blight. Plant Dis. 88:167-174.

Rasmusson, D. C., Wilcoxson, R. D. and Wiersma, J. V. 1993. Registration of 'Stander' barley. Crop Sci. 33:1403.

Rossnagel, B. G., Bhatty, R. S., Scoles, G. J. and Harvey, B. L. 1998. CDC Freedom 2-row hulless barley. URL http:// wheat.pw.usda.gov/ggpages/BarleyNewsletter/41/CDCFreedom.html [13 August 2021].

Sameri, M., Takeda, K. and Komatsuda, T. 2006. Quantitative trait loci controlling agronomic traits in recombinant inbred lines from a cross of oriental- and occidental-type barley cultivars. Breed. Sci. 56:243-252.

SAS Institute. 2004. SAS system viewer 9.1. SAS Institute Inc., Cary, NC, USA.

Shands, R. G. 1939. Chevron, a barley variety resistant to stem rust and other diseases. Phytopathology 29:209-211.

Sinha, R. C. and Savard, M. E. 1996. Comparison of immunoassay and gas chromatography methods for the detection of the mycotoxin deoxynivalenol in grain samples. Can. J. Plant Pathol. 18:233-236. 
Sinha, R. C., Savard, M. E. and Lau, R. 1995. Production of monoclonal antibodies for the specific detection of deoxynivalenol and 15-acetyldeoxynivalenol by ELISA. J. Agric. Food. Chem. 43:1740-1744.

Takeda, K. and Heta, H. 1989. Establishing the testing method and a search for the resistant varieties to Fusarium head blight in barley. Jpn. J. Breed. 39:203-216 (in Japanese).

Urrea, C. A., Horsley, R. D., Steffenson, B. J. and Schwarz, P. B. 2005. Agronomic characteristics, malt quality, and disease resistance of barley germplasm lines with partial Fusarium head blight resistance. Crop Sci. 45:1235-1240.

Vivar, H. E., Gilchrist, L., Hayes, P., Zongzhen, L., Steffenson, B., Franco, J. and Henry, M. 1997. Head scab resistant barley for malting and food. Cereal Res. Commun. 25:693-697.

Xue, A. G., Armstrong, K. C., Voldeng, H. D., Fedak, G. and Babcock, C. 2004. Comparative aggressiveness of isolates of Fusarium spp. causing head blight on wheat in Canada. Can. J. Plant Pathol. 26:81-88.

Yoshida, M., Kawada, N. and Nakajima, T. 2007. Effect of infection timing on fusarium head blight and mycotoxin accumulation in open- and closed-flowering barley. Phytopathology 97:1054-1062.

Zhou, X., Chao, M. and Liang, X. 1991. Screening and testing of barley varieties for scab resistance Acta Phytophylacica Sin. 18:261-265 (in Chinese). 